\title{
UNIÕES BINACIONAIS ENTRE ESPANHÓIS E BRASILEIROS EM ESPANHA
}

\author{
Juan Carlos Checa \\ Universidad de Almería, Almeria, Espanha \\ Ángeles Arjona \\ Universidad de Almería, Almeria, Espanha
}

\begin{abstract}
Resumo O objetivo deste artigo é conhecer os principais tipos de relações matrimoniais que se estabelecem entre pessoas de nacionalidade espanhola e brasileira. Os dados foram obtidos a partir da consulta ao Movimento Natural da População (MNP). Os resultados mostram que as uniões entre os nacionais do Brasil residentes em Espanha e a população espanhola são um fenómeno em crescimento desde 2005. Destacam-se especialmente as relações entre os espanhóis e as brasileiras. Conclui-se, também, que as uniões homossexuais são mais frequentes entre homens brasileiros e espanhóis do que entre mulheres de ambos os países. Da mesma forma, pode-se comprovar que as uniões homossexuais entre as duas nacionalidades, de 2005 a 2010, são mais heterogâmicas que as estabelecidas pelos heterossexuais.
\end{abstract}

Palavras-chave: homossexualidade, heterossexualidade, casamentos mistos, mercado matrimonial, homogamia, heterogamia.

Abstract The the aim of this paper is to identify the main marriage patterns that develop between people of Spanish and Brazilian nationality. The data are obtained from Natural Population Movement (MNP). The results show that unions between nationals of Brazil residents in Spain and Spaniards are a growing phenomenon since 2005. Particularly noteworthy are the links established between Spanish and Brazilian. And homosexual unions are more prevalent among Brazilian and Spanish men than among women of both countries. Similarly, it is observed that homosexual mixed marriages from 2005 to 2010 are more heterogamous than heterosexual mixed marriages.

Keywords: homosexuality, heterosexuality, intermarriage, marriage market, homogamy, heterogamy.

Résumé Le but de cet article est d'identifier les principaux modèles de mariage qui sont établis entre les personnes de nationalité espagnole et brésilienne. Les données ont été obtenues à partir du Mouvement naturel de la population (MNP). Les résultats montrent que les mariages entre ressortissants du Brésil et de l'Espagne sont un phénomène croissant depuis 2005. Particulièrement remarquables sont les liens établis entre les espagnols et les brésiliennes. Et les unions homosexuelles sont plus fréquentes entre des hommes brésiliens et espagnols que parmi les femmes brésiliennes des deux pays. De même, on observe que les mariages mixtes homosexuels de 2005 à 2010 sont plus hétérogames que celles établis par des hétérosexuels.

Mots-clés: homosexualité, hétérosexualité, mariages mixtes, le marché matrimonial, l'homogamie, l'hétérogamie.

Resumen El objetivo de este trabajo es identificar los principales patrones matrimoniales que se establecen entre las personas de nacionalidad española y brasileña. Los datos se obtienen a partir del Movimiento Natural de la Población (MNP). Los resultados muestran que las uniones entre nacionales brasileños residentes en España y los españoles son un fenómeno creciente desde 2005. Particularmente digno de mención son los vínculos que se establecen entre el español y la brasileña. Y las uniones homosexuales son más frecuentes entre hombres brasileños y españoles que entre mujeres de ambos países. De igual modo, se observa que las uniones mixtas homosexuales desde 2005 hasta 2010 son más heterógamas que las heterosexuales.

Palabras-clave: homosexualidad, heterosexualidad, matrimonios mixtos, mercado matrimonial, homogamia, heterogamia. 


\section{Introdução}

A chegada, paulatina, entre 1990 e 2015, de imigrantes a Espanha mudou as dinâmicas demográficas e sociais do país. Uma delas foi a nupcialidade entre nacionais e estrangeiros. De acordo com o Instituto Nacional de Estadística de Espanha (INE), em 1994 os matrimónios mistos eram 4,7\% e em 2009 esse número subiu para $21,3 \%$.

Através dos brasileiros que se deslocaram para Espanha é também possível analisar o tema dos matrimónios mistos com espanhóis, visto que os brasileiros residentes em Espanha eram 2709 em 1998, em 2005 o número subiu até 54.115, para alcançar os 117.808 em 2010. Ao mesmo tempo que aumentou o número de brasileiros a residir em Espanha, aumentou também o número de matrimónios mistos com espanhóis, já que, segundo o Movimento Natural da População (MNP), publicado pelo INE, em 1998 houve 400 casamentos, em 2005, 1335 e em 2009 o número subiu para 3140. Este aumento culminou no facto de as brasileiras serem atualmente a principal nacionalidade nos casamentos entre estrangeiras e espanhóis. Em segundo lugar, aparecem as colombianas e, em terceiro lugar, os matrimónios com as imigrantes provenientes de antigos países da União Soviética, nomeadamente, Rússia, Ucrânia e Lituânia.

É por tudo isto que o objetivo deste artigo é múltiplo: (1) fazer uma análise estatística do número de casamentos entre espanhóis e brasileiros em Espanha; (2) conhecer as principais relações matrimoniais que se estabelecem entre ambas as nacionalidades e comparar a homogamia - definida, principalmente, pelo facto de os cônjuges possuírem condição social e económica similar - e a heterogamia - situação em que existem diferenças sociais e económicas entre os cônjuges nas uniões heterossexuais e homossexuais binacionais; já que a partir de 3 de julho de 2005 entrou em vigor a Lei n. 3/2005, que regula o direito de contrair matrimónio entre pessoas do mesmo sexo em Espanha (Platero, 2010).

Assim, a partir dos dados disponibilizados pelo Movimento Natural da População (MNP), pretende-se conhecer a estrutura de oportunidades de contacto (Alotta, 2000; Camarero, 2010; Gil, 2010; Gonsoulin e Fu, 2010; Iceland e Nelson, 2010; Kalmijn, 1998, 2010; Cortina et al., 2008; González, 2006; Oppenheimer, 1997; Sánchez-Domínguez et al., 2011) entre os membros de ambos os países, a qual está determinada, principalmente, pelo tamanho do grupo, a idade dos membros, a sex ratio, a posição no mercado laboral, ou pelas preferências da população autóctone por determinados grupos (Huijnk et al., 2010; Kalmijn, 1998, 2010; Setién e Vicente, 2007). Em consequência, pretende-se adensar as reflexões em torno de um fenómeno demográfico incipiente, mas em crescimento.

No entanto, os números não assinalam somente um processo de aumento contínuo de matrimónios binacionais. Eles revelam, também, através das suas normas, dinâmicas sociais como a reprodução das estruturas e das desigualdades sociais ou a interação entre os distintos grupos. ${ }^{1}$ Mais concretamente, os matrimónios

1 Para conhecer os processos de integração dos brasileiros em Espanha veja, entre outros, Solé, Calvanti y Parella (2011) e Finotelli et al. (2013). 
internacionais consideram-se um indicador chave para analisar a integração social dos imigrantes na sociedade de acolhimento (Gordon, 1964; Meng e Gregory, 2005; Nielsen et al., 2007; Kalmijn, 1998, 2010; Quian e Lichter, 2007).

A razão justifica-se pelas potenciais consequências, visto que o matrimónio é uma relação íntima e em muitos casos duradoura, que elimina fronteiras ou distâncias étnicas e raciais (Davis, 1991), evita conflitos identitários e ajuda a eliminar os preconceitos (Xie et al., 2003). Além disso, significa uma melhoria socioeconómica para o cônjuge estrangeiro, derivada da melhor posição laboral e social que apresenta, em grande parte dos casos, o autóctone (Meng e Gregory, 2005; Rosenfeld, 2007). Por outras palavras, é um sinal de aceitação da igualdade por parte dos membros de grupos diferentes e contribui para a integração social. Evidentemente, a ausência de matrimónios intergrupais não implica, por si, a rejeição de outros grupos ou a consolidação da desigualdade.

Finalmente, com este trabalho procuramos oferecer alguns números e argumentos que possam cobrir o vazio empírico que existe na explicação das uniões entre pessoas destes dois países. Estamos conscientes, em todo o caso, das significativas limitações às quais temos de fazer frente, a saber: importante dose de invisibilidade social, principalmente nas uniões homossexuais, e falta de estatísticas que abordem o fenómeno na sua totalidade, o que dificulta quantificar o número real de casais e as suas características.

Assim, após a introdução, apresentamos os principais elementos teóricos que guiam e explicam o fenómeno dos matrimónios mistos. O objetivo desta secção é de exposição (e não de discussão). Em sequência (2.․ secção), referem-se as fontes utilizadas. Em terceiro lugar, surge uma secção para apresentação de resultados. Aqui assinalamos como mais significativo o facto de as uniões entre os nacionais do Brasil residentes em Espanha e a população autóctone terem aumentado no período compreendido entre 2005 e 2009.

Verificamos, ainda, que: (a) nos matrimónios binacionais entre espanhóis e brasileiros predomina o matrimónio heterossexual em que o homem é espanhol e a mulher é brasileira; (b) nos matrimónios binacionais entre homossexuais espanhóis e brasileiros predominam os que se realizam entre homens; (c) pode-se comprovar que as uniões homossexuais mistas são mais heterogâmicas que as estabelecidas pelos heterossexuais, quanto à idade, nível académico e ocupação dos cônjuges. Finalmente, os dados permitem concluir que entre mulheres e homens separados de matrimónios heterossexuais que vêm a ter uniões homossexuais é mais frequente tal acontecer entre mulheres. O texto termina com uma discussão dos dados e a apresentação de conclusões.

\section{Enquadramento teórico}

A fundamentação teórica que guia o estudo deste fenómeno estrutura-se em torno dos padrões e fatores de eleição do cônjuge (Kalmijn, 1998). Em geral, os modelos matrimoniais surgem da interação entre três forças sociais: as preferências individuais por certas características do cônjuge; a influência do grupo social de que são membros e as 
características do ambiente; e, por último, as limitações do próprio mercado matrimonial em que se procura o cônjuge (Rodríguez, 2004). Portanto, o processo de escolha de um(a) parceiro(a) e a formação do casamento é um fenómeno multidimensional determinado pela combinação e inter-relação de todos esses fatores.

Tomando como referência uma lógica racional (racional choice), a escolha do(a) parceiro(a) estabelece-se a partir do momento em que são avaliados os custos e benefícios (cf. Becker, 1974). Igualmente, o matrimónio constitui-se como um intercâmbio de recursos - afetivos, materiais, etc. - entre dois indivíduos que são, na maioria das ocasiões, perfeitamente avaliados e, portanto, aplicam critérios de maximização de resultados na hora de escolher o cônjuge através da informação disponível. Neste processo, as pessoas "compram" o melhor cônjuge que conseguem atrair com os recursos que possam oferecer. Quando se casam, os cônjuges juntam esses recursos para produzir bens ou produtos familiares, como o bem-estar económico, o status e o afeto (Kalmijn, 1998).

Recentemente, Blossfeld e Timm (2004) falaram da racionalidade limitada, tanto pelo tempo de procura como pela informação obtida, o que implica que a comparação entre candidatos nem sempre é possível. Por isso, nessa eleição intervêm, além da decisão individual, elementos próprios do contexto: composição da população de vizinhança, capital social, legislação matrimonial, etc. Como resultado desta perspetiva aparece o conceito de mercado matrimonial, entendido como o espaço físico e simbólico de encontros entre sujeitos que estão dispostos a contrair matrimónio (Cabré, 1994; McDonald, 1995).

Além disso, há regras e o funcionamento de intercâmbio que se baseia na existência de oferta e procura, submetidas a condições de competência que se regulam por decisões racionais e livres. Apesar de os "matrimónios por amor" serem um indicador de uma sociedade moderna, industrial e urbana, este critério ("amor") não é o único presente no momento de eleger o cônjuge. Existem "estratégias individuais, induzidas por considerações sociais e económicas" (Rodríguez, 2004: 33-34). Contudo, os mecanismos que se ativam para encontrar o equilíbrio não passam pelo preço, mas sim por outros atributos, como idade, sexo, estado de solteiro, nacionalidade (Gaspar, 2012), etc. Por isso, os esforços teóricos posteriores dão atenção à regulação do mercado matrimonial misto, onde se destacam as questões económicas (Nakosteen e Zimmer, 2001), culturais (Kalmijn, 1998) e, logicamente, a orientação sexual: heterossexual vs. homossexual.

Os recursos socioeconómicos dizem respeito à possibilidade de melhorar a posição social. A teoria da troca sustém que os sujeitos pertencentes a minorias étnicas que contraem matrimónio com outros do grupo maioritário, experimentam uma melhoria na sua posição social (Heer, 1974; Monahan, 1976; Shoen e Wooldredge, 1989; Wirth e Goldhamer, 1944). Portanto, as pessoas com melhores níveis académicos, altos rendimentos e trabalhos prestigiados são os candidatos mais atrativos em termos de seleção no mercado matrimonial (Nakosteen e Zimmer, 2001), produzindo-se uma heterogamia. Por esse motivo, na literatura existente encontra-se geralmente uma correlação positiva entre os matrimónios mistos e os rendimentos ou o nível académico do cônjuge nacional (Korenman e Neumark, 1991; Nakosteen e Zimmer, 1987). 
Por outro lado, os recursos culturais. A similaridade cultural produz-se em três tipos de níveis: primeiro, a similaridade dos valores e opiniões, que leva a uma confirmação mútua do comportamento e da visão do mundo de cada um; segundo, a similaridade dos gostos, que se torna atrativa porque incrementa as oportunidades de participar em atividades conjuntas; e, finalmente, a similaridade do conhecimento, que cria uma base comum para a conversa, melhorando o entendimento mútuo.

Deste modo, a similaridade cultural conduz à atração pessoal e também motiva as pessoas para estabelecerem relações de longo prazo (Kalmijn, 1998: 398-399). Em suma, diz respeito, por um lado, a valores, opiniões, estilos de vida ou visão do mundo e, por outro lado, no caso de apresentarem competências linguísticas diferentes, ao domínio do idioma. Deste modo, os principais candidatos para estabelecer os matrimónios binacionais são aqueles que compartilham padrões culturais similares (cf. Kalmijn, 1998) e apresentam melhores competências linguísticas, visto que aumentam as oportunidades de contacto e comunicação com a população autóctone. Por conseguinte, com o passar das gerações, os imigrantes irão experimentando um processo de assimilação cultural e domínio do idioma, facto que tem entre os seus resultados o matrimónio intergrupal, fruto de processo de assimilação estrutural. Os imigrantes, após aprenderem o idioma, começam a estabelecer relações com os autóctones, além dos centros de trabalho, especialmente nos espaços públicos (vizinhanças, parques, etc.), centros de lazer (bares, cafeterias), associações, etc., contactos esses que possibilitam e favorecem as relações afetivas (cf. Gordon, 1964).

No entanto, como foi demonstrado nas avaliações posteriores desta teoria, este processo não se produz nem de maneira tão mecânica, nem em todos os coletivos. É um modelo que se aproxima mais do que aconteceu com os imigrantes europeus nos Estados Unidos do que do experimentado pelos latinos e asiáticos. No entanto, para quase todos os grupos, a exogamia incrementa-se com o passar das gerações de imigrantes (Giorgas e Jones, 2002; Lieberson e Waters, 1988; Lievens, 1998), de maneira que os filhos e netos dos primeiros imigrantes apresentam maiores taxas de uniões matrimoniais com os nacionais (Bermúdez, 2007; Rodríguez, 2004).

Assim, as uniões homossexuais binacionais também aumentarão com o passar do tempo, pois, se no princípio estas se mantiveram entre pessoas da mesma nacionalidade, posteriormente foram-se consolidando com membros de outros lugares (Andersson et al., 2006; Festy e Digoix, 2004). Não devemos esquecer que o comportamento matrimonial endogâmico, em alguns grupos e independentemente da sua orientação sexual, pode ser atribuído à influência das famílias (Hurtado, 1995; Hwang et al., 1997; Qian et al., 2001), quando constroem um discurso baseado na "distância" cultural entre os grupos, destacando, especialmente, as diferenças religiosas - muçulmanos, hindus, entre outros.

Outro dos elementos teóricos explicativos dos matrimónios internacionais parte do conceito de oportunidade, entendida como a probabilidade de se encontrar com membros do ex-grupo. Os elementos que compõem as oportunidades de contacto ficam definidos principalmente pelo tamanho do grupo (Anderson e Sáenz, 1994; Hwang et al., 1997; Lievens, 1998), pois este tem influência na oportunidade de se encontrar com membros do próprio grupo. Assim, os grupos com grande 
representação experimentam maiores doses de endogamia (Anderson e Sáenz, 1994; Hwang et al., 1997; Pagnini e Morgan, 1990). Evidentemente, nos matrimónios entre pessoas do mesmo sexo esta variável torna-se fundamental, visto que a homossexualidade é uma orientação sexual existente em menor número que a heterossexual.

E em terceiro lugar, a dimensão residencial (Iceland e Nelson, 2010): quando os índices de segregação são elevados, a endogamia é maior, devido à menor probabilidade de contactar com membros de outros grupos. Não obstante, para as uniões do mesmo sexo este elemento não somente é minimizado, mas sim, em alguns casos, a consolidação de espaços residenciais onde gays e lésbicas se concentram, indistintamente da nacionalidade, possibilita as uniões endogâmicas e exogâmicas atendendo à origem.

No entanto, na explicação da formação de matrimónios mistos destaca-se o papel que desempenha o estado no seu processo de regulação do fenómeno, assim como a religião e a família. O primeiro define e identifica os diferentes grupos, inclusive com um determinado status jurídico, e regulariza a forma e os requisitos para contrair matrimónio. Em Espanha, o status jurídico do cônjuge estrangeiro é fundamental: uma situação de irregularidade entorpece as uniões; o estado vigia para que todos os matrimónios internacionais se concebam por amor e não para a obtenção dos papéis que legitimem a presença do imigrante. Por outro lado, tal como assinalámos antes, os matrimónios entre pessoas do mesmo sexo podem formalizar-se desde julho de 2005. Como se sabe, são poucos os estados que reconhecem as uniões entre pessoas do mesmo sexo, o que as obriga a contrair matrimónio principalmente com pessoas daqueles lugares onde a regulação é positiva ante a sua orientação sexual.

De outra forma, as religiões são - ou foram - instituições que definem as linhas de socialização das pessoas e a sua estrutura identificativa. Apesar de os matrimónios mistos heterossexuais se manifestarem mais permissivos, não o são com os homossexuais (Hooghiemstra, 2003; Kulzycki e Lobo, 2002; Sherkat e Creek, 2010; Sherkat et al., 2011), para marcar o acontecimento como algo contra natura e antirreligioso.

Acresce que a família é o principal agente de socialização onde se consolida a transmissão de normas e valores, os quais podem inibir a exogamia heterossexual e homossexual. De facto, existem vários argumentos teóricos que explicam o papel da família na hora de estabelecer relações dos nacionais com pessoas estrangeiras.

O primeiro, a partir da teoria da igualdade, sustém que o indivíduo procura pessoas similares a si mesmo, especialmente no que se refere ao âmbito ocupacional, académico, religioso ou linguístico. Neste caso, as redes sociais desempenham um papel fundamental, pois regulam as normas e sancionam os comportamentos não normativos. Assim, a endogamia está mais enfatizada em grupos que querem ou necessitam de manter a coesão grupal, tal como os valores próprios (Clark-Ibañez e Felmlee, 2004; Huijnk et al., 2010; Sniderman e Hagendoorn, 2007). Inclusive, as famílias destacadamente conservadoras e com menor nível académico são mais propensas a apresentar atitudes preconceituosas e negativas para o ex-grupo (Lambert e Chasteen, 1997); portanto, entendem o matrimónio homogâmico como um valor em si mesmo. 
Não obstante, para o caso das uniões entre pessoas do mesmo sexo, as investigações mostraram (Andersson et al., 2006; Festy e Digoix, 2004) que são mais heterógamas que as heterossexuais, principalmente no que se refere à idade, tal como entre os seus níveis educativos e de nacionalidade. Logicamente, as redes sociais são fundamentais para aceder às uniões, mas o caráter transgressor que tem a homossexualidade, para além de oportunidades mais reduzidas pelo menor número de pessoas com esta orientação sexual, faz com que a escolha do(a) parceiro(a) seja menos seletiva atendendo a certos padrões.

Sobre isto, Schwartz e Graf (2009) oferecem como explicação para a maior heterogamia dos homossexuais, além da referida menor oferta de homossexuais, as expectativas diferentes em matéria de fecundidade, visto que estes matrimónios têm menos filhos que os heterossexuais e assim podem eleger parceiros(as) mais velhos(as). Também têm um menor controlo social das famílias e por isso instituem uniões mais livres.

Finalmente, o processo de eleição do cônjuge e a formação de matrimónios mistos são um processo multidimensional determinado por diferentes fatores inter-relacionados que se podem concretizar na preferência individual perante a eleição do(a) parceiro(a), a influência do grupo social e as limitações ou possibilidades do mercado matrimonial.

\section{Fontes de dados}

As fontes estatísticas que, em Espanha, disponibilizam dados sobre os matrimónios entre espanhóis e estrangeiros - matrimónios mistos - são várias. Entre as mais utilizadas nos estudos estão o Censo de População de 2001 e o Movimento Natural de População (MNP), ambos elaborados pelo Instituto Nacional de Estadística (INE). ${ }^{2}$ Para a elaboração deste texto decidimos utilizar o MNP, ${ }^{3}$ por vários motivos: primeiro, porque o censo informa, a cada dez anos, de todos os casais corresidentes que se autodeclaram como tal, independentemente de viverem juntos (por exemplo, em "união de facto") ou serem casados. Porém, o MNP dá informação sobre os matrimónios constituídos em Espanha anualmente.

Em segundo lugar, tanto o censo de 2001 como o de 2011 oferecem informação procedente de uma pesquisa. ${ }^{4}$ Para este último, os dados procedem de uma

2 O Inquérito da População Ativa (IPA) elaborado pelo INE espanhol desde 1964 com periodicidade trimestral, o Inquérito de Fecundidade (IF), elaborado pelo INE espanhol - nos anos de 1977, 1985 e 1999 - ou o inquérito à habitação da União Europeia (Phogue), elaborado pela Comissão Europeia (1996-2004), também oferecem informação sobre os matrimónios mistos.

3 Movimiento Nacional de Población. URL: http://www.ine.es/jaxi/menu.do?type=pcaxis\&path $=/$ t20/e302\&file=inebase

4 O censo é elaborado pelo INE espanhol, a cada dez anos. A URL é: http://ine.es/ intercensal/. Neste link poderá encontrar informação sobre a população espanhola desde 1842 até 2011. 
mostra extraída de $12 \%$ da população..$^{5} \mathrm{O}$ MNP recolhe com exatidão os casamentos registados. Além disso, proporciona dados sobre certas características dos cônjuges, como, por exemplo, nacionalidade, sexo, profissão ou idade; inclusive, nos últimos anos recolheram-se dados sobre o nível académico, que correspondem aos objetivos deste trabalho.

Refira-se que o MNP apresenta sérias limitações: não regista os casais que apesar de não casados vivem juntos, muito frequentes, por exemplo, entre os latino-americanos (cf. Castro, 2001). Por outro lado, não reúne os matrimónios mistos ou endogâmicos realizados no estrangeiro por pessoas que atualmente vivem em Espanha. Acresce que aquela publicação recolhe dados sobre matrimónios que puderam ter como incentivo, para além do amor, a obtenção da permissão de residência do cônjuge estrangeiro e reduzir o tempo de residência exigido para conseguir a nacionalidade.

Referindo-nos ao objetivo específico deste texto, vamos, ainda assim, utilizar o MNP. O período analisado oscila entre 2005 e 2009 principalmente por dois motivos. Em primeiro lugar, é o ano em que se legalizaram os matrimónios homossexuais, logo até esse momento não temos informação deste tipo de união. Segundo, porque será nestes últimos anos que se produz o grande aumento de matrimónios entre pessoas destas duas nacionalidades, visto que nos últimos 15 anos, $70 \%$ dos matrimónios com pessoas procedentes do Brasil se produziram nos últimos cinco. ${ }^{6}$

O universo dos matrimónios celebrados em Espanha desde 2005 até 2009 é de 996.313. Focamos-nos principalmente nas 12.345 uniões que se estabeleceram nesse período entre autóctones e nacionais do Brasil.

Especificando, e tendo em conta a forma de o INE registar os matrimónios mistos (cônjuge A corresponde a homem e cônjuge $B$ a mulher) agrupamos, para todos os casos, o cônjuge A com a nacionalidade espanhola e o B com a nacionalidade brasileira. Assim, os dados apresentados neste texto correspondem aos matrimónios registados em Espanha e produzidos entre, por um lado, população de nacionalidade espanhola e, por outro lado, população de nacionalidade brasileira, residente em Espanha, independentemente do seu lugar de nascimento.

$\mathrm{Na}$ análise teremos em conta as principais características sociodemográficas dos cônjuges que oferece o MNP: estado civil, idade, nível académico e profissão. Por último, assinale-se que alguns quadros do ponto seguinte (resultados) não dizem respeito a todo o universo, visto que, em múltiplos casos, por omissão do cônjuge ou porque não consta nos dados que oferece o INE, não existe informação de certas variáveis para todos os cônjuges, sobretudo, o nível académico.

5 Para conhecer o projeto metodológico do censo de 2011 pode consultar: http://www.ine.es/censos2011_datos/cen11_datos_metodologia.htm

6 Veja-se os arquivos de microdados em: http://ine.es/dyngs/INEbase/es/operacion.htm?c=Estadistica_C\&cid=1254736176999\& $\&$ menu=resultados\&secc $=1254736195438 \&$ id $=1254735573002$

SOCIOLOGIA, PROBLEMAS E PRÁTICAS, n.ํ 85, 2017, pp. 67-87. DOI:10.7458/SPP2017855043 


\section{Resultados}

Nesta parte, primeiramente tratamos de quantificar o alcance do fenómeno dos matrimónios mistos, bem como as principais características que apresentam, principalmente pelo tipo de orientação sexual.

A primeira constatação, que se desdobra no quadro 1, é que o número de matrimónios mistos entre os nacionais do Brasil e de Espanha está em paralelo com o aumento da população brasileira em Espanha. Segundo os diferentes dados oferecidos pelo INE, em 2005 havia em Espanha 54.115 brasileiros; 1,4\% da população estrangeira ( $0,1 \%$ da população total recenseada em Espanha). Nesse mesmo ano, o número de matrimónios estabelecidos entre a população de ambos os países foi de 1335, ou seja, 5,8\% dos matrimónios mistos celebrados em Espanha e 0,63\% do total de matrimónios.

Em 2009, a população brasileira residente em Espanha foi de 126.185 habitantes, o que significa 2,2\% da população estrangeira (e $0,26 \%$ da população total), e os matrimónios mistos constituídos foram 3140, o que equivale a 10,2\% dos matrimónios mistos e a 1,78\% do total dos matrimónios celebrados no país. Por outras palavras, o aumento populacional dos cidadãos do Brasil foi acompanhado, proporcionalmente, em matéria matrimonial.

No entanto, existem importantes diferenças no número de uniões segundo a orientação sexual dos cônjuges, visto que no período analisado os matrimónios heterossexuais chegam aos 11.573; o número dos homossexuais alcança os 772; em ambos os casos tal corresponde a uma tendência ascendente.

De qualquer forma, o tipo de matrimónio mais frequente entre os nacionais de Espanha e Brasil, durante o período de 2005-2009, corresponde a um matrimónio misto heterossexual em que o homem é espanhol e a mulher brasileira (9948 casos), seguido pelas 1625 uniões onde a mulher é espanhola e o homem brasileiro. Finalmente, no que respeita nos matrimónios homossexuais, 652 celebraram-se entre homens e 120 entre mulheres.

Centrados nas características sociodemográficas que desenham o mercado matrimonial, verificamos, relativamente ao estado civil dos cônjuges procedentes do Brasil (cf. quadro 2), que nos matrimónios heterossexuais se provém de um estado civil de solteiro(a) (83,8\% para as mulheres brasileiras e $90,2 \%$ para os homens). Ainda que em menor escala exista um importante número de uniões onde o cônjuge do Brasil anteriormente teve outra relação; assim é para 15,2\% das mulheres e $9,7 \%$ nos homens. Por outro lado, as uniões homossexuais, na grande maioria, apresentam também um estado imediatamente anterior de solteiro(a) (96,9\% dos homens e $91,7 \%$ das mulheres).

Em menor escala, sobressai que 8,3\% das mulheres separadas/divorciadas se casam com outras mulheres, contra $2,9 \%$ dos homens. Diferenças entre géneros assinalam que, em certos casos, as mulheres que atualmente apresentam uniões homossexuais procedem de matrimónios heterossexuais mais que os homens - visto que para ambos os casos as suas primeiras núpcias eram anteriores a 2005, data em que se regulariza o matrimónio homossexual. 
Quadro 1 Evolução da população de nacionalidade brasileira residente na Espanha e número de matrimónios mistos de brasileiros(as) com espanhóis (espanholas) (2005-2009)

\begin{tabular}{lrrrrr}
\hline & 2005 & 2006 & 2007 & 2008 & 2009 \\
\hline População do Brasil $\left(^{*}\right)$ & 54.115 & 72.441 & 90.161 & 116.548 & 126.185 \\
Matrimónios mistos heterossexuais $\left(^{* *}\right)$ & 1.310 & 1.953 & 2.537 & 2.868 & 2.905 \\
Matrimónios mistos homossexuais $\left(^{* *}\right)$ & 25 & 138 & 149 & 225 & 235 \\
\hline
\end{tabular}

$\left(^{*}\right)$ Os dados são cumulativos.

$\left.{ }^{* *}\right)$ Número de matrimónios anuais (não cumulativos).

Fonte: INE e MNP. Elaboração própria.

Quadro 2 Matrimónios de brasileiros(as) segundo o seu estado civil anterior com espanhóis (espanholas) (2005-2009) (valores absolutos e percentagens) ( $\left.{ }^{*}\right)$

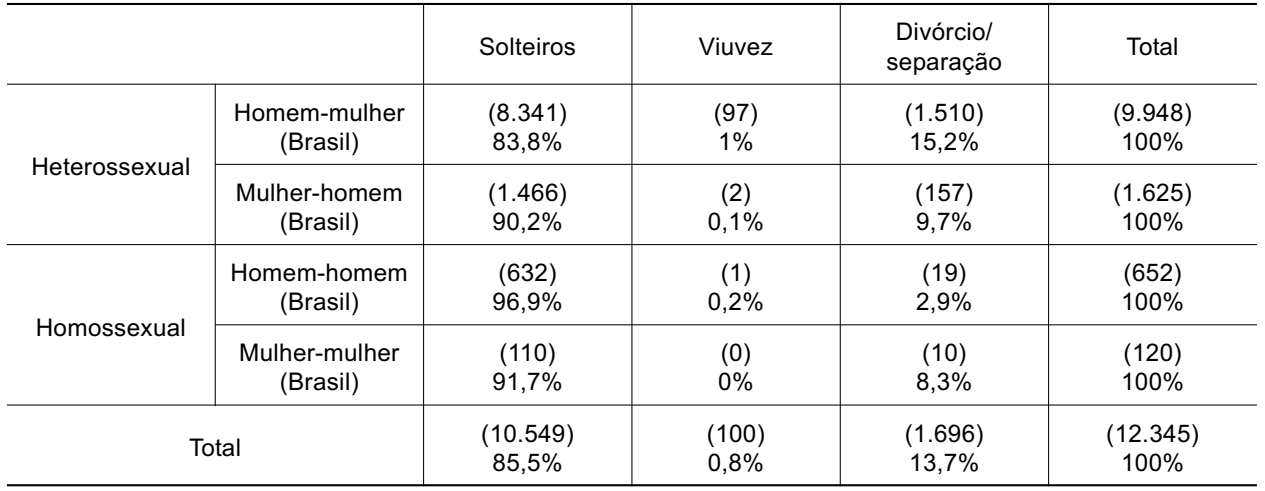

${ }^{*}$ ) $\mathrm{O}$ cônjuge $\mathrm{A}$ corresponde à nacionalidade espanhola e o $\mathrm{B}$ à nacionalidade brasileira.

Fonte: MNP. Elaboração própria.

Centremo-nos agora na análise do estado civil dos(as) esposos(as). No caso dos(as) solteiros(as) procedentes do Brasil, estes(as) casam-se, na sua maioria (75\%), com outros(as) solteiros(as) espanhóis (espanholas) e 24\% com autóctones procedentes de outras núpcias. Por outro lado, os(as) divorciados(as) do Brasil unem-se principalmente com espanhóis (espanholas) solteiros(as) (58,2\%). Por último, os viúvos(as) casam-se especialmente com solteiros(as) espanhóis (espanholas) (57\%).

Outra das variáveis fundamentais explicativas de qualquer tipo de matrimónio é a idade dos cônjuges. A idade média dos cônjuges brasileiros é de 30,1, contra os 36 anos dos espanhóis. Mais especificamente, nos matrimónios heterossexuais as mulheres brasileiras alcançam uma média de idade de 30,5 anos e os homens de 28,6 . Por outro lado, os homens homossexuais têm 29,4 anos de média e as mulheres chegam aos 31. Dito de outra forma, as mulheres brasileiras, independentemente da orientação sexual da união, são mais velhas do que os homens.

Por isso, nos matrimónios heterossexuais entre espanhóis (espanholas) e brasileiros(as), 90,5\% têm entre 19 e 40 anos. Para os homens brasileiros no mesmo 
Quadro 3 Matrimónios de brasileiros(as) segundo a sua idade com espanhóis (espanholas) (2005-2009) (valores absolutos e percentagens) $\left(^{*}\right)$

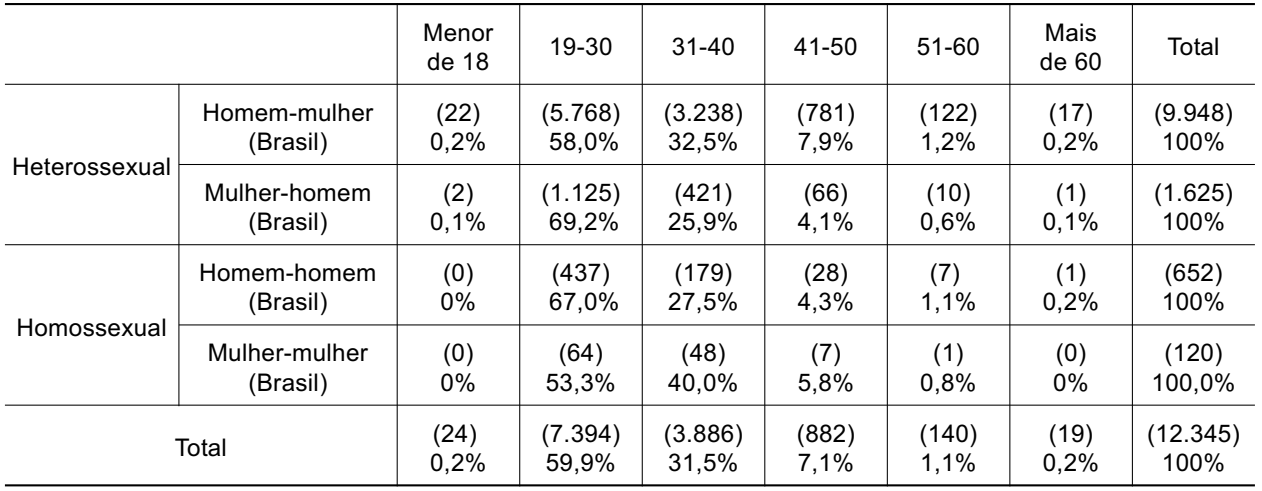

${ }^{*}$ ) $\mathrm{O}$ cônjuge $\mathrm{A}$ corresponde à nacionalidade espanhola e o $\mathrm{B}$ à nacionalidade brasileira.

Fonte: MNP. Elaboração própria.

período, a cifra alcança 95,1\%, ainda que com idades mais avançadas - mais de 41 anos - e casam-se menos que elas. Resultados similares alcançam as uniões homossexuais, de forma que $94,5 \%$ dos homens brasileiros e $93,3 \%$ das mulheres se concentram entre 19 e 40 anos (Cf. quadro 3).

Porém, quando comparamos as idades dos(as) seus (suas) esposos(as), verificamos que nas idades jovens - até aos 30 anos - em quase todos os casos, os cidadãos(ãs) do Brasil casam-se, maioritariamente, com espanhóis (espanholas) mais velhos(as) que eles(as). Assim, por exemplo, os(as) menores de 18 anos casam-se em $87,5 \%$ das ocasiões com um(a) espanhol(a) mais velho(a). Não obstante, conforme se avança em idade, a tendência para se casar com um(a) espanhol(a) de idade similar, ainda que a partir dos 51 anos, é mais frequente que os brasileiros(as) se casem mais com espanhóis (espanholas) mais jovens, sobretudo nas uniões homossexuais.

Como vimos nas páginas anteriores, o matrimónio é considerado um elemento importante no momento de experimentar a mobilidade social. O quadro 4, que mostra o número de nacionais do Brasil que se casam com pessoas de nacionalidade espanhola considerando o sexo e as habilitações, revela que, no caso dos homens, a percentagem maioritária possui estudos secundários $(44,2 \%)$, face a $38 \%$ que tem só estudos primários e 16,2\% que detêm estudos universitários. Por outro lado, verifica-se o número de mulheres brasileiras que se unem com espanholas, sendo pouco mais da metade dos casos as que declaram ter só estudos primários (51,7\%); ter estudos secundários corresponde a $26,7 \%$, e universitários a $21,7 \%$.

Quanto aos matrimónios heterossexuais, existem algumas diferenças assinaláveis. Em primeiro lugar, se para ambos os sexos a maioria tem apenas estudos primários, este nível é mais frequente entre as mulheres $(58,1 \%)$ frente a $45,4 \%$ dos homens. Em segundo lugar, e como consequência do anterior, 38,5\% e $14,2 \%$ dos brasileiros que se casam com espanholas têm estudos secundários e universitários, respetivamente. Por outro lado, o número de espanhóis que se 
Quadro 4 Matrimónios de brasileiros(as) segundo o nível académico com espanhóis (espanholas) (2005-2009) (valores absolutos e percentagens) $\left(^{*}\right)$

\begin{tabular}{|c|c|c|c|c|c|c|c|}
\hline & Analfabeto & $\begin{array}{l}\text { Sabe ler } \\
\text { e escrever }\end{array}$ & $\begin{array}{l}\text { Estudos } \\
\text { primários }\end{array}$ & $\begin{array}{c}\text { Estudos } \\
\text { secundários }\end{array}$ & $\begin{array}{c}\text { Estudos } \\
\text { universitários }\end{array}$ & Total \\
\hline \multirow{2}{*}{ Heterossexual } & Homem-mulher & $\begin{array}{c}(3) \\
0,1 \%\end{array}$ & $\begin{array}{l}(112) \\
2,8 \%\end{array}$ & $\begin{array}{l}(2.303) \\
58,1 \%\end{array}$ & $\begin{array}{c}(1.121) \\
28,3 \%\end{array}$ & $\begin{array}{c}(427) \\
10,8 \%\end{array}$ & $\begin{array}{c}(3.966) \\
100 \%\end{array}$ \\
\hline & Mulher-homem & $\begin{array}{c}(1) \\
0,1 \%\end{array}$ & $\begin{array}{l}(12) \\
1,7 \%\end{array}$ & $\begin{array}{c}(322) \\
45,4 \%\end{array}$ & $\begin{array}{c}(273) \\
38,5 \%\end{array}$ & $\begin{array}{l}(101) \\
14,2 \%\end{array}$ & $\begin{array}{l}(709) \\
100 \%\end{array}$ \\
\hline \multirow{2}{*}{ Homossexual } & Homem-homem & $\begin{array}{c}(1) \\
0,3 \%\end{array}$ & $\begin{array}{c}(4) \\
1,2 \%\end{array}$ & $\begin{array}{c}(122) \\
38,0 \%\end{array}$ & $\begin{array}{c}(142) \\
44,2 \%\end{array}$ & $\begin{array}{c}(52) \\
16,2 \%\end{array}$ & $\begin{array}{l}(321) \\
100 \%\end{array}$ \\
\hline & Mulher-mulher & $\begin{array}{l}(0) \\
0 \%\end{array}$ & $\begin{array}{l}(0) \\
0 \%\end{array}$ & $\begin{array}{c}(31) \\
51,7 \%\end{array}$ & $\begin{array}{c}(16) \\
26,7 \%\end{array}$ & $\begin{array}{c}(13) \\
21,7 \%\end{array}$ & $\begin{array}{c}(60) \\
100 \%\end{array}$ \\
\hline \multicolumn{2}{|c|}{ Total } & $\begin{array}{c}(5) \\
0,1 \%\end{array}$ & $\begin{array}{l}(128) \\
2,5 \%\end{array}$ & $\begin{array}{c}(2.778) \\
54,9 \%\end{array}$ & $\begin{array}{c}(1.552) \\
30,7 \%\end{array}$ & $\begin{array}{l}(593) \\
11,7 \%\end{array}$ & $\begin{array}{c}(5.056) \\
100 \%\end{array}$ \\
\hline
\end{tabular}

${ }^{*}$ ) $\mathrm{O}$ cônjuge $\mathrm{A}$ corresponde à nacionalidade espanhola e o $\mathrm{B}$ à nacionalidade brasileira.

Fonte: MNP. Elaboração própria.

casam com brasileiras que têm estudos secundários é de $28,3 \%$, baixando para $10,8 \%$ quando a escolaridade é de nível universitário. Em consequência, o nível académico dos(as) brasileiros(as) que se unem com pessoas do mesmo sexo é um pouco superior ao que apresentam os heterossexuais.

Ora, quando comparamos os níveis académicos entre os cônjuges pode-se comprovar que se produz certa ascensão entre os nacionais do Brasil. Dito de outra forma, $40 \%$ dos analfabetos nacionais do Brasil casam-se com pessoas possuidoras de um nível académico igual ou superior aos estudos secundários. Da mesma forma, os chegados deste país ibero-americano com nível de estudos primários em $33 \%$ dos casos casam-se com pessoas de mais elevado nível académico. Não obstante, estas diferenças reduzem-se quando falamos de matrimónios homossexuais.

O segundo indicador considerado para medir o movimento social através do matrimónio é a profissão. Tal como acontece no caso anterior, existem importantes diferenças entre os sexos nos matrimónios homossexuais e heterossexuais. Como provam os dados do quadro 5 , as mulheres brasileiras que se casam com espanhóis na sua maioria fazem-no com aqueles que desempenham trabalhos de colarinhos azuis $(51,3 \%)$, e a percentagem que exerce um emprego de colarinho branco $(40,6 \%)$ aumenta para quase o dobro em relação às suas compatriotas mulheres.

Nas uniões homossexuais, voltam a ser os homens que, comparativamente às mulheres, apresentam melhores percentagens no desempenho de atividades de colarinho branco no mercado laboral (34,1\% frente a $27,5 \%)$.

No entanto, ao comparar estes dados com os dos seus cônjuges espanhóis, observa-se que $81,2 \%$ dos nacionais do Brasil de colarinho branco se casam com um cônjuge espanhol da mesma categoria profissional; ou seja, menos de $20 \%$ da população brasileira une-se com um espanhol de menor categoria profissional, situação que diz respeito maioritariamente a uniões homossexuais e principalmente de mulheres. Dito de outra forma, segundo o MNP, $54,5 \%$ dos chegados do Brasil com 
Quadro 5 Matrimónios de brasileiros(as) segundo a sua ocupação com espanhóis (espanholas) (2005-2009) (valores absolutos e percentagens) $\left(^{*}\right)$

\begin{tabular}{l|c|c|c|c|c|c|c}
\hline \multicolumn{2}{l|}{} & $\begin{array}{c}\text { Colarinho } \\
\text { branco }\end{array}$ & $\begin{array}{c}\text { Colarinho } \\
\text { azul }\end{array}$ & $\begin{array}{c}\text { Pessoa } \\
\text { que vive } \\
\text { de rendas }\end{array}$ & Desempregados & Estudantes & Total \\
\hline \multirow{3}{*}{ Heterossexual } & Homem-mulher & $(1.967)$ & $(6.376)$ & $(9)$ & $(502)$ & $(185)$ & $(9.039)$ \\
& $21,8 \%$ & $70,5 \%$ & $0,1 \%$ & $5,6 \%$ & $2,0 \%$ & $100 \%$ \\
& Mulher-homem & $(593)$ & $(748)$ & $(1)$ & $(94)$ & $(23)$ & $(1.459)$ \\
& $40,6 \%$ & $51,3 \%$ & $0,1 \%$ & $6,4 \%$ & $1,6 \%$ & $100 \%$ \\
\hline \multirow{5}{*}{ Homossexual } & Homem-homem & $(203)$ & $(319)$ & $(1)$ & $(46)$ & $(26)$ & $(595)$ \\
& $34,1 \%$ & $53,6 \%$ & $0,2 \%$ & $7,7 \%$ & $4,4 \%$ & $100 \%$ \\
& Mulher-mulher & $(30)$ & $(69)$ & $(0)$ & $(5)$ & $(5)$ & $(109)$ \\
& $27,5 \%$ & $63,3 \%$ & $0 \%$ & $4,6 \%$ & $4,6 \%$ & $100 \%$ \\
\hline
\end{tabular}

$\left(^{\star}\right)$ O cônjuge $A$ corresponde à nacionalidade espanhola e o $B$ à nacionalidade brasileira.

Fonte: MNP: Elaboração própria.

colarinho azul casam-se com um colarinho branco deixando clara a movimentação social ascendente, uma realidade mais frequente entre as brasileiras.

\section{Discussão}

O objetivo deste texto é quantificar o fenómeno dos matrimónios mistos entre pessoas procedentes do Brasil e os espanhóis autóctones, colocando principalmente ênfase nas tendências que apresentam os matrimónios heterossexuais e homossexuais a partir de uma série de variáveis básicas. Concretamente, oferecer dados e reflexões sobre um fenómeno demográfico incipiente, mas claramente em crescimento.

A primeira revelação dos dados diz respeito ao aumento do número de uniões entre os nacionais de ambos os países, tanto de características heterossexuais como homossexuais, destacando-se, principalmente as uniões entre os espanhóis e as brasileiras.

Vários são os motivos que explicam este fenómeno: o primeiro é a escassez ou abundância dos(as) candidatos(as). Por isso, na maior parte dos matrimónios que se produzem em Espanha ambos os cônjuges são espanhóis (até 2009, segundo mostram os dados do MNP, os matrimónios mistos nunca superaram os $14 \%$ do total de matrimónios celebrados em Espanha). Mas, no caso dos matrimónios mistos heterossexuais, quanto maior é o défice de um sexo estrangeiro, mais se incrementa a endogamia ou vice-versa. Daí que as uniões maioritárias que se produzem entre espanhóis e estrangeiras são fundamentalmente com latino-americanas, visto que existe um importante excedente, já que são mais numerosas que os homens dessa mesma origem e, portanto não podem unir-se com 
pessoas do mesmo grupo. Por exemplo, no ano de 2009, os dados do INE mostram como há 118.516 mais mulheres latino-americanas do que homens, sobressaindo as bolivianas, colombianas e brasileiras. Acontece desta forma que as brasileiras se convertem, atualmente, no grupo com mais uniões com espanhóis. Como consequência, as características demográficas da imigração brasileira favorecem este tipo de matrimónios mistos, especialmente os estabelecidos entre os espanhóis e as brasileiras, havendo para esse mesmo ano de 2009, segundo o INE, 15.721 mais brasileiras do que homens.

Isto faz com que exista uma relação positiva entre o desequilíbrio de efetivos e a diferença nos níveis de endogamia. Dado que, como se mencionou anteriormente, as uniões (racional choice) atuam como um mercado que se fundamentam na oferta e procura entre sujeitos que estão dispostos a contrair matrimónio (cf. Cabré, 1994; McDonald, 1995), no que atuam determinadas condições e mecanismos para encontrar o equilíbrio. Portanto, quanto maior o excedente da oferta, mais exogamia existe. Assim, o total de matrimónios protagonizados entre 2005 e 2009 com ambos os cônjuges do Brasil é de 602, contra os 12.345 mistos. Por outras palavras, a composição dos matrimónios mistos entre os espanhóis (espanholas) e os(as) brasileiros(as) em Espanha fica explicada, em grande parte, pelo tamanho e o desequilíbrio de efetivos masculinos e/ou femininos.

Menção especial merecem as diferenças verificadas entre homens e mulheres com uniões homossexuais, que, como vimos, são mais frequentes entre homens brasileiros e espanhóis que entre mulheres de ambos os países. É uma situação que abre possíveis linhas ou hipóteses de trabalho para investigações futuras, visto que cremos que tem mais a ver com as características das uniões que com o número oferta - de homossexuais de um sexo ou outro. De tal forma que teríamos que procurar explicações nas motivações diferentes que uns e outros manifestam na hora de contrair matrimónio ou declarar corresidência.

Assim, por exemplo, Andersson et al. (2006), para a Suécia e a Noruega, falam de uma proteção contra a sida, com maior incidência nos homens. Mas também tem lógicos argumentos que podem estar relacionados com a visão que oferece ao exterior a homossexualidade relativamente ao sexo, apresentando uma menor transparência na oferta em mulheres. Esta pode ficar coberta no país de destino, tanto pela pressão dos seus compatriotas como pela sociedade de chegada, dado que ao elemento estrangeiro se acrescenta o de homossexual. Lembre-se a diferente valorização das características dos candidatos, visto que, como veremos mais tarde, sobre as mulheres brasileiras recaem uma série de estereótipos que podem travar as relações com outras mulheres espanholas.

O segundo elemento que explica o aumento das uniões internacionais entre Brasil e Espanha está intimamente relacionado com a atitude ou orientação mais ou menos favorável para o grupo, visto que determina, na maioria das ocasiões, a adoção de certos comportamentos e condutas. Por fim, condiciona os contatos e relações sociais intergrupais. Neste caso, a opinião da população brasileira é positiva: a aproximação do idioma, associada a determinadas manifestações culturais que foram importadas para Espanha: Carnaval, samba, capoeira, etc. 
Para, além disso, no estudo sobre Cooperação e América Latina, de setembro de 2006, do Centro de Investigações Sociológicas (CIS), mede-se o grau de simpatia e as nacionalidades das quais os espanhóis se sentem mais próximos e identificados: o Brasil encontra-se em quinto lugar, atrás da Argentina, do México, de Cuba e da Venezuela. Na mesma linha, e de acordo com os dados do Latinobarómetro VIII, realizado também pelo CIS, o Brasil ocupa o quarto lugar entre os países da América Latina que mais confiança inspiram entre a população espanhola, depois da Argentina, do México e do Chile.

Além de tudo isto, cabe uma menção especial à representação social diferente por razão de género da comunidade brasileira, dotando-a de uma sensualidade e exotismo especial, associado à mulher brasileira - sobretudo a mulata - que está identificada como um símbolo ou ícone sexual (Malheiros, 2007; Masanet e Baeninger, 2010). Contudo, em certas ocasiões essa perceção conduz, paralelamente, a uma conotação negativa, associando as brasileiras com prostituição, o que se traduz em aversão e hostilidade da parte de algumas mulheres autóctones. Por outro lado, os cidadãos do Brasil, tal como sustentam Masanet e Baeninger (2010) num estudo qualitativo, representam socialmente os(as) espanhóis (espanholas) como pessoas com um caráter temperamental e impulsivo. Além disso, valorizam a festa e a diversão, tal como a alegria e a atitude mais aberta em comparação com outros nacionais europeus.

Concluindo, para os cidadãos de ambos os países, no início existem mais semelhanças que diferenças, o que facilita as relações intergrupais, as quais se poderão consolidar com matrimónios mistos. Portanto, como defendem Blossfled e Timm (2004) quando falam de racionalidade limitada, o tempo destinado para eleger um(a) parceiro(a) e a informação obtida são maiores com aqueles em que se reconhecem afinidades. Inclusive, os homossexuais, sabedores da dificuldade do contacto pela rejeição de uma parte da sociedade, tratam de criar alternativas que permitam os encontros. Se para os matrimónios mistos heterossexuais a segregação residencial é um limitador de contactos com os autóctones, a concentração de homossexuais num determinado lugar funciona em sentido oposto. Assim acontece no bairro madrileno de Chueca, considerado o de maior concentração de homossexuais em Espanha.

Em suma, e para o caso concreto das uniões homossexuais, ao aumento paulatino das uniões pelos motivos já citados, pode acrescentar-se como explicação a regulação deste tipo de uniões, o que permitiu visualizar uma realidade que estava mais ou menos velada, não somente pelas barreiras jurídicas, mas também pela pressão social existente, que implica uma rejeição das práticas e relações homossexuais.

Juntamente com os elementos culturais, também as características económicas do país são um elemento para o estabelecimento de relações. O mercado laboral espanhol apresenta uma grande dose de etnossegmentação (Arjona, 2006; Veira et al., 2011), entendida esta como a estratificação laboral atendendo à procedência ou nacionalidade dos trabalhadores. Para o nosso caso, as brasileiras empregam-se, na sua maioria, em serviços de contacto humano - trabalhos domésticos ou cuidado de anciãos e crianças; e eles nos setores de serviços ou construção, nos quais o 
contacto direto e físico é mais frequente com espanhóis ${ }^{7}$ que em outros coletivos inseridos em postos de trabalho, como o transporte de mercadorias ou a agricultura, nos quais o contacto com o autóctone é mais limitado. Por isso, é mais fácil estabelecer relações estáveis e duradouras com pessoas que vemos ou com quem temos relações, ainda que sejam laborais.

Juntamente com o tema da posição económica, tal como evidenciaram Cortina (2007), Cortina et al. (2009) e Rodríguez (2004), para os matrimónios mistos em Espanha existe uma importante homogamia conjugal; ou seja, estão-se esbatendo as diferenças que havia com as profissões laborais e o nível académico dos cônjuges. Além disso, o matrimónio clássico entre uma mulher com um baixo nível escolar e um homem com um bom nível económico já não é o modelo que predomina nos matrimónios. É suficiente recordarmos que mais de três quartos dos cidadãos brasileiros de colarinho azul se casam com um espanhol com uma profissão similar. Por outras palavras, o matrimónio está a perder parte da capacidade que tinha para estabelecer um movimento social ascendente. Ora bem, não faltam casos de procedentes do Brasil que desenvolvem profissões de colarinho azul (54,5\%) que se casam com um espanhol que desempenha uma profissão mais qualificada, sobretudo no caso das mulheres heterossexuais. Da mesma forma, não é claro que isto ocorra de uma forma tão marcada nas uniões entre pessoas com o mesmo sexo, especialmente e para o nosso caso com as uniões entre homens, visto que a oferta populacional não é tão numerosa como a existente para os matrimónios heterossexuais.

Também o estado civil atua como pedra angular no momento de relações matrimoniais. A maioria dos matrimónios mistos formou-se entre pessoas solteiras. Ainda que os dados exibam que o estado de solteiro(a) é uma estratégia matrimonial mais acentuada entre os homossexuais que entre os heterossexuais. É uma situação que se explica, por um lado, devido ao reduzido tempo desde que se efetuam este tipo de matrimónios, o que minimiza a probabilidade de se casar com um divorciado. Logicamente, não importa com que anterioridade se teve outro parceiro(a), inclusive partilhando residência, mas o anterior vazio legal impede de se falar de divorciado(a).

No entanto, é preciso assinalar que, possivelmente, parte da percentagem de homossexuais brasileiros(as) casados(as) com espanhóis (espanholas) provém de matrimónios heterossexuais prévios, sobretudo, pelo escasso tempo desde que se produzem este tipo de uniões com reconhecimento jurídico tanto em Espanha como no Brasil. É uma situação que se dá com mais intensidade no caso das mulheres.

Para terminar, a idade converte-se numa variável importante para explicar a confirmação de casais. Segundo Cortina et al. (2009), em Espanha, os casais mistos heterossexuais são mais heterógamos quanto à idade que os formados exclusivamente por espanhóis: em mais de $50 \%$ das uniões entre homem espanhol e

7 Mais ainda, a proximidade laboral, como assinala González (2006) para os Estados Unidos, pode ser que, em alguns casos, favoreça uma homossexualidade supervivente e obrigada pela subordinação e dependência laboral de um dos cônjuges e, noutros, que a união sirva para conseguir um estatuto jurídico que sem o matrimónio é quase impossível adquirir. 
mulher estrangeira, aqueles são pelo menos três anos mais velhos que elas. Da mesma maneira, como vimos para o nosso caso, a população vinda do Brasil e casada com autóctones é normalmente mais jovem que os nacionais nos períodos de idade avançada, e maior nos intervalos até aos 31 anos, mostrando uma grande dose de heterogamia, principalmente, entre os homossexuais, visto que o mercado matrimonial é mais reduzido. Por outras palavras, os limites tão justos que tem o mercado matrimonial homossexual binacional faz com que a oferta e a procura superem algumas das barreiras culturais básicas, como a de ter uma idade parecida.

\section{Conclusões}

Em síntese, os números convidam às seguintes conclusões gerais. Em primeiro lugar, constatou-se um aumento progressivo de matrimónios entre nacionais do Brasil e de Espanha que acompanham o aumento da população brasileira neste país. Em segundo lugar, verificou-se que existem diferenças entre os tipos de matrimónios estabelecidos, destacando-se, sobretudo, os heterossexuais entre um espanhol e uma brasileira. Nos matrimónios binacionais entre homossexuais espanhóis e brasileiros predominam os que se realizam entre homens.

A terceira conclusão revela que, entre mulheres e homens separados de matrimónios heterossexuais, que vêm a ter uniões homossexuais tal situação é mais frequente entre mulheres. Em quarto lugar, não se seguem as mesmas regras entre heterossexuais e homossexuais, sendo as destes últimos algo mais heterógamas, especialmente no que se refere à idade, ao nível académico e à profissão. Acresce que nos casamentos binacionais heterossexuais a mobilidade social através da escolaridade do(a) parceiro(a) parece ter pouca importância.

Portanto, esta situação evidencia uma possibilidade de trabalho futuro (cf. Sassler, 2005), principalmente quando o fenómeno das uniões homossexuais mistas e endogâmicas - experimente um percurso temporal mais longo, para assim conhecer o papel que têm as diferentes variáveis demográficas no momento de estabelecer preferências por uns grupos ou por outros. Naturalmente, sem esquecer que são precisas novas fontes de informação que eliminem as limitações das atuais, que somente permitem uma visão parcial do fenómeno.

\section{Referências bibliográficas}

Alotta, Stefania (2000), "Matrimoni misti: la scelta di un partner straniero", Studi Emigrazione, 37 (137), pp. 41-66.

Anderson, Robert, e Rogelio Sáez (1994), “Structural determinants of Mexican American marriages, 1975-1980", Social Science Quarterly, 75, pp. 414-430.

Andersson, Gunnar, et al. (2006), “The demographics of same-sex marriages in Norway and Sweden", Demography, 43 (1), pp. 79-98.

Arjona, Ángeles (2006), Los Colores del Escaparate, Barcelona, Icaria. 
Becker, Gary (1974), "A theory of marriage", em T. Schultz (org.), Economics of the Family, Chicago, The University of Chicago Press, pp. 93-112.

Bermúdez, Elba (2007), Historias de Unión y de Amor en Parejas Mixtas que Residen en la Comunidad Valenciana. Relatos desde la Masculinidad y la Feminidad, Cuadernos de Investigación CEIM, 3.

Blossfled, Hans, e Andreas Timm (2004), Who Marries Whom? Educational Systems as Marriage Markets in Modern Societies, Amesterdão, Kluwer Publishers.

Cabré, Anna (1994), “Tensions imminents en els mercats matrimonials”, em Joaquín Nandal (coord.), El Món Cap a on Anem, Barcelona, Eumo, pp. 31-56.

Camarero, Luis (2010), “Transnational families in Spain: family structures and the reunification process", Empiria, 19, pp. 39-71.

Castles, Stephen, Hein de Haas, e Mark J. Miller (2003), The Age of Migration. International Population Movements in the Modern World, Londres, Palgrave Macmillan.

Castro, Teresa (2001), “Matrimonios sin papeles en Centroamérica: persistencia de un sistema dual de nupcialidad", em R. Bixby (org.), Población del Istmo 2000, Costa Rica, Centro de Población, pp. 5-26.

CIS - Centro de Investigaciones Sociológicas (2006), Cooperación y América Latina, Madrid, Ministerio de la Presidencia de España, disponível em: http://www.cis.es/cis/opencm/ES/1_encuestas/estudios/ver.jsp?estudio=6258 (última consulta em maio de 2017).

CIS - Centro de Investigaciones Sociológicas (2006), Latinobarómetro, Madrid, Ministerio de la Presidencia de España, disponível em: http://www.cis.es/cis/opencm/ES/1_encuestas/estudios/ver.jsp?estudio=14035 (última consulta em maio de 2017).

Clark-Ibañez, Marisol, e Diane Felmlee (2004), “Interethnic relationships: the role of social network diversity", Journal of Marriage and the Family, 66, pp. 293-305.

Cortina, Clara (2007), ¿Quién se Empareja con Quién? Mercados Matrimoniales y Afinidades Electivas en la Formación de la Pareja en España, Barcelona, Universitat Autònoma de Barcelona, tese de doutoramento.

Cortina, Clara, Albert Esteve, et al. (2008), "Marriage patterns of the foreing-born population in a new country of immigration: the case of Spain", International Migration Review, 42 (4), pp. 877-902.

Cortina, Clara, Thais García, et al. (2009), “Migración, ocupación y matrimonio: una aproximación a las relaciones de género de las parejas mixtas en España", Estudios Demográficos y Urbanos, 24 (2), pp. 293-321.

Davis, James Floyd (1991), Who is Black? One Nation's Definition, State College, PA, Pennsylvania State University Press.

Festy, Patrick, e Mary Digoix (2004), Same-Sex Couples, Same-Sex Partherships $\mathcal{E}$ Homosexual Marriages. A Focus on Cross-National Differentials, Paris, INED.

Finotelli, Cláudia, Diego Acosta, et al. (2013), Migração Brasil-Europa. A Situação dos Migrantes Brasileiros na Espanha e Portugal e de Portugueses e Espanhóis no Brasil. Aspectos Legais e Vivências, Viena, International Centre for Migration Policy Development.

Freyre, Gilberto (1998), Casa-Grande e Senzala, Rio de Janeiro, Record. 
Gaspar, Sofia (2012), "Patterns of bi-national couples across five EU countries", Sociologia, Problemas e Práticas, 70, pp. 71-89, disponível em: http://spp.revues.org/1135 (última consulta em maio de 2016).

Gil, Fernando (2010), “New Europeans or transnational European Union citizens with multiple citizenship or cultural backgrounds: the Spanish case", Papers to XVII ISA World Congress of Sociology.

Giorgas, Dimitras, e Francis Jones (2002), “Intermarriage patterns, social cohesion among first, second and later generation Australians", Journal of Population Economics, 19, pp. 47-64.

Gonsoulin, Margaret, e Xuanning Fu (2010), Intergenerational Assimilation by Intermarriage. Hispanic and Asian Immigrants, Nova Iorque, Taylor \& Francis Group.

González, Gloria (2006), “Heterosexual fronteras: immigrant mexicanos sexual vulnerabilities, and survival", Sexuality Research and Social Policy, 3 (3), pp. 67-82.

Gordon, Milton (1964), Assimilation in American Life. The Role of Race, Religion and National Origins, Nova Iorque, Oxford University Press.

Heer, David (1974), “The prevalence of Black-White marriage in the United States, 1960 and 1970", Journal of Marriage and the Family, 36, pp. 246-258.

Hooghiemstra, Erna (2003), Trouwen over de Grens. Achtergronden van Partnerkeuze van Turken en Marokkanen in Nederland, [Casar-se na fronteira: escolha de parceiro de turcos e marroquinos na Holanda], Haia, Cultureel Planbureau.

Huijnk, Willem, et al. (2010), “Intermarriage attitude among ethnic minority and majority groups in the Netherlands: the role of family relations and immigrant characteristics", Journal of Comparative Family Studies, 41 (3), pp. 389-412.

Hurtado, Aida (1995), "Variations, combinations and evolutions: Latino families in the United States", em R. Zambrana (org.), Understanding Latino Families, Londres, Sage, pp. 40-61.

Hwang, Sean, et al. (1997), "Structural and assimilationistic explanations of Asian American intermarriage", Journal of Marriage and the Family, 59, pp. 758-772.

Iceland, John, e Kyle Nelson (2010), The Residential Segregation of Mixed-Nativity Married Couples, Nova Iorque, Population Association of America.

INE - Instituto Nacional de Estadística. URL: http://ine.es/

Kalmijn, Matthijs (1998), “Intermarriage and homogamy: causes, patterns, trends”, Annual Review of Sociology, 24, pp. 395-421.

Kalmijn, Matthijs (2010), “Consequences of racial intermarriage for children's social integration", Sociological Perspectives, 53 (2), pp. 271-286.

Korenman, S., e D. Neumark (1991), “Does marriage really make men more productive?", The Journal of Human Resources, 26, pp. 282-307.

Kulzycki, Andrzej, e Arun Lobo (2002), "Patterns, determinants and implications among Arab American", Journal of Marriage and the Family, 64, pp. 202-210.

Lambert, Alan, e Alison Chasteen (1997), “Perceptions of disadvantage versus conventionality: political values and attitudes toward the elderly versus Blacks", Personality and Social Psychology Bulletin, 23, pp. 469-481.

Lieberson, Stanley, e Mary Waters (1988), From May Stands. Ethnic and Racial Groups in Contemporary America, Nova Iorque, Sage Foundation. 
Lievens, John (1998), “Interethnic marriage: bringing in the context through multilevel modelling", European Journal of Population, 14, pp. 117-155.

Malheiros, Jorge (2007), “Os brasileiros em Portugal - a síntese do que sabemos”, em Jorge Malheiros (org.), Imigração Brasileira em Portugal, Lisboa, ACIDI, pp. 53-65.

Masanet, Erika, e Rosana Baeninger (2010), “Imágenes recíprocas y estereotipos entre la población brasileña y autóctona en el contexto multicultural español", Convergencia, 17 (53), pp. 151-174.

McDonald, Meter (1995), “L'équilibre numérique entre hommes et femmes et le marché matrimonial: le point sur la question", Population, 50 (6), pp. 1579-1590.

Meng, Xien, e Robert Gregory (2005), “Intermarriage and the economic assimilation of immigrants", Journal of Labor Economics, 23, pp. 135-175.

Mohahan, Thomas (1976), "An overview of statistics on interracial marriage in the United States, with data on its extent from 1963-1970", Journal of Marriage and the Family, 38, pp. 223-231.

Movimiento Nacional de Población. URL: http://ine.es/dyngs/INEbase/es/operacion.htm?c=Estadistica_C\&cid=125473617699 9\&menu $=$ ultiDatos\&id $=1254735573002$

Nakosteen, Robert, e Michael Zimmer (1987), “Marital status and earnings of young men", Journal of Human Resources, 22, pp. 248-268.

Nakosteen, Robert, e Michael Zimmer (2001), “Spouse selection and earnings: evidence of marital sorting", Economic Inquiry, 39, pp. 201-213.

Nielsen, Helena, et al. (2007), “The effect of marriage on education of immigrants: evidence from a policy reform restricting spouse import", IZA Discussion Paper, N.. 2899 .

Oppenheimer, Valerie (1997), "Women's employment and the gain to marriage: the specialization and trading model", Annual Review of Sociology, 23, pp. 431-453.

Pagnini, Deanna, e Philip Morgan (1990), “Intermarriage and social distance among US immigrants at the turn of the century", American Journal of Sociology, 96, pp. 405-432.

Platero, Raquel (2010), "Popping the question - politics and the same-sex marriages in Spain", Socialno delo, 49 (6), pp. 333-342.

Quian, Zhenchao, e Daniel Lichter (2007), “Social bondaries and marital assimilitaion: interpreting trends in racial and ethnic intermarriage", American Journal of Sociology, 72, pp. 68-94.

Quian, Zhenchao, et al. (2001), "Asian American interracial and interethnic marriages: differences by education and nativity", International Migration Review, 35, pp. 557-586.

Rodríguez, Dan (2004), Inmigración y Mestizaje Hoy. Formación de Matrimonios Mixtos y Familias Transnacionales de Población Africana en Cataluña, Barcelona, Universitat Autònoma de Barcelona.

Rosenfeld, Michael (2007), The Age of Innocence. Interracial Unions, Same-Sex Unions and the Changing American Family, Cambridge, MA, Harvard University Press.

Sánchez-Domínguez, María, et al. (2011), “Marriage strategies among immigrants in Spain", Revista Internacional de Sociología, monográfico 1, pp. 139-166.

Sassler, Sharon (2005), "Gender and ethnic differences in marital assimilation in the early twentieth century", International Migration Review, 39 (3), pp. 608-636. 
Setién, María, e Trinidad Vicente (2007), “Actitudes y comportamientos de la población ante los matrimonios mixtos en España", em A. Ibarrola, e Cl. Firth (orgs.), Migraciones en Un Contexto Global, Deusto, Universidad de Deusto, pp. 129-158.

Schwartz, Christine, e Nikki Graf (2009), "Assortative matching among same-sex and different-sex couples in the United States, 1990-2000", Demographic Research, 21 (28), pp. 843-878.

Sherkat, Darren, e Stacia Creek (2010), "Race, religion, and opposition to same-sex marriage", Social Science Quarterly, 91 (1), pp. 80-98.

Sherkat, Darren, et al. (2011), "Religion, politics, and support for same-sex marriage in the United States, 1988-2008", Social Science Research, 40 (1), pp. 167-180.

Shoen, Robert, e John Wooldredge (1989), "Marriage choices in North Carolina and Virginia, 1969-71 and 1979-81", Journal of Marriage and the Family, 1, pp. 465-481.

Sniderman, Paul, e Louk Hagendoorn (2007), When Ways of Life Collide. Multiculturalism and Its Discontents in the Netherlands, Princenton, Princenton University Press.

Solé, Carlota, Leonardo Cavalcanti, e Sonia Parella (2011), La Inmigración Brasileña en la Estructura Socioeconomica de España, Madrid, Secretaría de Estado de Inmigración.

Veira, Alberto, et al. (2011), “Los determinantes de la concentración étnica en el mercado laboral español”, Revista Internacional de Sociología, monográfico 1, pp. 219-242.

Wirth, Louis, e Herbert Goldhamer (1944), "The hybrid and the problem of miscegenation", em O. Kilenberge (org.), Characteristics of American Negro, Nova Iorque, Harper \& Brothers, pp. 249-260.

Xie, Yu, et al. (2003), "Economic potential and entry in to marriage and cohabitation", Demography, 40 (2), pp. 351-367.

Juan Carlos Checa. Professor titular de Sociologia, Universidad de Almería, Almeria, Espanha. E-mail: jcheca@ual.es

Ángeles Arjona. Professora titular de Antropologia Social, Universidad de Almería, Almeria, Espanha. E-mail: arjona@ual.es

Receção: 12 de setembro de 2014 Aprovação: 14 de fevereiro de 2017 
